(C) 2017 IEEE. Personal use of this material is permitted. Permission from IEEE must be obtained for all other uses, in any current or future media, including reprinting/republishing this material for advertising or promotional purposes, creating new collective works, for resale or redistribution to servers or lists, or reuse of any copyrighted component of this work in other works.

Digital Object Identifier (DOI): 10.1109/TIE.2017.2701758

IEEE Transaction on Industrial Electronics (Volume: 64, Issue: 11, Jan. 2017)

Integration of Large Photovoltaic and Wind System by Means of Smart Transformer

Rongwu Zhu

Giovanni De Carne

Fujin Deng

Marco Liserre

Suggested Citation

R. Zhu, G. De Carne, F. Deng and M. Liserre, "Integration of large photovoltaic and wind system by means of smart transformer," in IEEE Transactions on Power Electronics, vol. 64, no. 11, pp. 8928-8938, Nov. 2017. 


\title{
Integration of Large Photovoltaic and Wind System by Means of Smart Transformer
}

\author{
Rongwu Zhu, Member, IEEE, Giovanni De Carne, Member, IEEE, Fujin Deng, Member, IEEE, \\ and Marco Liserre, Fellow, IEEE
}

\begin{abstract}
Large renewable energy systems (RESs), e.g., photovoltaic (PV) and wind turbine (WT) are connected to grid usually weak, with long lines. This degrades power system stability and reliability. Additionally, the magnetic characteristic of conventional power transformer (CPT) implies a slow dynamic and leads to grid current harmonic too high when wind speed is low and irradiance is weak. This paper proposes a parallel connection of a solid-state transformer-based smart transformer and CPT to not only reduce the power rating but also to support the voltage amplitude and improve the grid current quality. The simulation and experimental results clearly verify the correctness and feasibility of the proposed strategy.
\end{abstract}

Index Terms-Renewable energy system, weak grid, reactive power support, total harmonic distortion (THD), smart transformer (ST).

\section{INTRODUCTION}

L arge photovoltaic (PV) and wind power (WP)-based renewable power generation systems (RPGSs) have been greatly developed in recent decades. Generally, large WP and PV plants are geographically located in rural places, far away from the main grid. Therefore, the connected transmission grid is relatively weak, which leads to less power transfer capacity and low stability $[1,2]$. Moreover, the penetration increase of RPGS degrades the power grid stability and reliability, and challenges the grid voltage control [3], mostly in case of RPGSs operation connected to a weak grid [4, 5].

Beside above issues, high total harmonic distortion (THD) of injected current is also evident for large PV and WP system, due to the step-up transformer, which has been not widely discussed in the current literatures. Large PV and WP systems are integrated into power grid by means of conventional power transformers (CPT), as shown in Fig. 1. The CPT electromagnetic characteristic impacts on the power quality in MV grid [6-10]. When the wind speed is low and the irradiance is weak, the power produced by the WP and PV is small. This makes the exciting current component relatively large with respect to the active current component.

Manuscript received July 31, 2016; revised January 11, 2017 and March 31, 2017; accepted April 12, 2017. This work was supported by the European Research Council under the European Union's Seventh Framework Programme (FP/2007- 2013)/ERC Grant Agreement 616344 HEART-the Highly Efficient And Reliable smart Transformer.

R. Zhu, G. De Carne and M. Liserre are with the Chair of Power Electronics, Christian-Albrechts-Univeristy of Kiel, 24118 Kiel, Germany (email: rzh@tf.uni-kiel.de; gdc@tf.uni-kiel.de; liserre@ieee.org).

F. Deng is with the School of Electrical Engineering, Southeast University, Nanjing, 210096, China. (e-mail: dfjqfa@163.com).
Therefore, weak grid problem and high current THD are two typical issues for large RPGSs. Some strategies have been proposed to suppress the CPT harmonic during normal conditions [6, 10] and faulty conditions [9].

On the other hand, in order to increase the RPGSs penetration and improve voltage stability, reactive power compensation was required $[11,12]$. Due to power rating limit of converter used to control RPGSs, extra devices are required to increase grid support capability [13]. Several solutions have been proposed in industry and academy: HVDC systems [1316], reactive power support and voltage regulation devices [13, 17-22]. The HVDC system can avoid issues of weak grid, but at high costs. In contrast, the extra reactive power support or voltage regulation device is a cost-effective choice.

The on-load tap-changing transformer (OLTCT) can actively regulate load voltage, but its controllability is constrained by the limited number of switches for hour and step change low dynamic. Thus, the combination of OLTCT and extra reactive power compensators or energy storage systems has been proposed to improve the voltage regulation $[19,20]$.

A hybrid transformer (HT), based on the mixed parallel and series connection of power converter and CPT, has been proposed to achieve active and reactive power flow control and harmonic compensation [25, 26]. However, the series converter current must be sized as the CPT, and, moreover, the magnetizing current impact of the CPT still remains [26].

STATCOM is the most common way to support grid voltage $[17,18]$. The STATCOM, usually is connected to medium voltage grid by a series step-up transformer. However, being CPT-connected to the grid, has the same problem of large distorted current in grid when the required injected reactive current is small. For this reason, the STATCOM cannot contribute to the grid current quality caused by the CPT exciting current during low power production of RPGSs.

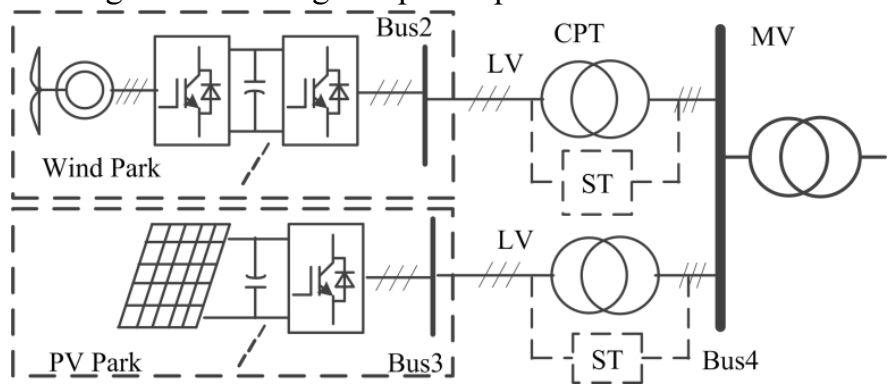

Fig. 1 RPGS configuration with ST and CPT connected in parallel

The solid-state transformer (SST) has been applied for traction purpose by ABB, SIEMENS, ALSTOM, due to the advantages of low volume and weight [21-24]. The smart transformer (ST) [27, 28], instead, aims to provide ancillary 

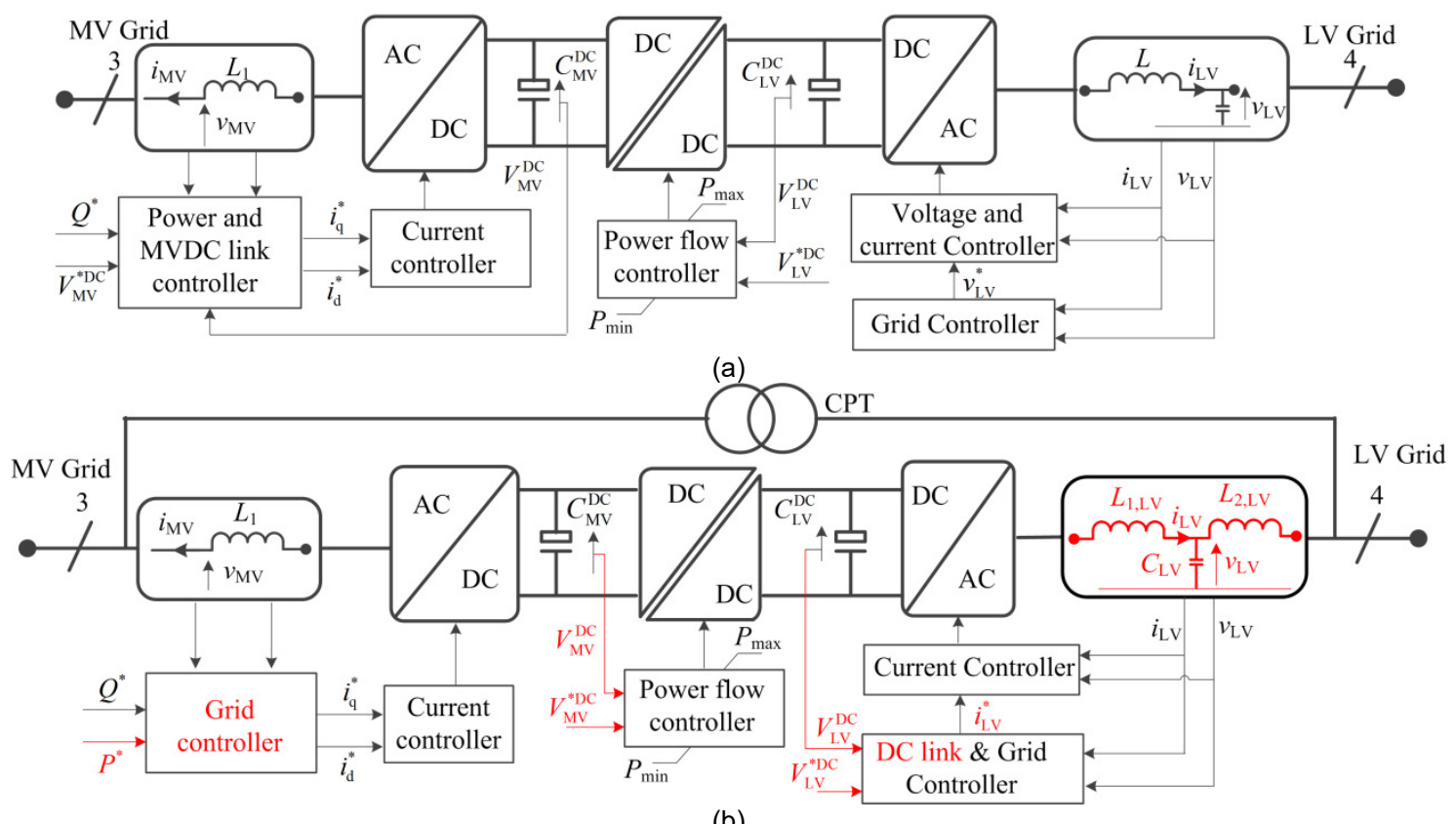

(b)

Fig. 2 ST control: (a) classic configuration, (b) ST parallelized with conventional transformer. (The controller changes have been marked in red)

services to the distribution grid [28-32], more than simply adapting the voltage level from MV to LV grids, like in the SST case. Compared to the HT, the ST is more flexible to offer frequency support, voltage control, reactive power compensation, power flow regulation, power congestion control. However, if the CPT is entirely replaced by ST, even though it can solve the harmonic problem, it leads to an increase of installation costs compared to CPT or HT solutions.

In order to cope with the cost problem, this paper proposes a parallel connection of the ST and CPT to offer services with a reduced investment costs. In this case the voltage support and power quality improvement has been considered as services.

This paper is organized as follows. The ST classic control and the proposed control is compared in Section II. The electromagnetic characteristic of the CPT is studied in Section III. The improved strategy is proposed in Section IV. The harmonic suppression of the proposed strategy is validated by experiments in Section V. Section VI concludes this paper.

\section{SMART TRANSFORMER CONCEPT}

This section describes briefly the ST classic control and introduces new control for parallel connection of ST and CPT.

\section{A. Smart Transformer Classic Control}

As shown in Fig. 2(a), in the LV grid, the ST controls the voltage in order to provide balanced and sinusoidal waveforms, independently from the current demanded by the LV loads. The ST is able to provide services to the distribution and transmission grid, performing load and generation control in the downstream LV grid [33, 34].

The DC/DC stage transforms the voltage from MV to LV level. In the ST case, the dual active bridge (DAB) has been adopted. The DAB allows the power flow control from MV to LV grid to maintain LV DC link voltage at its nominal value.

The MV AC/DC stage, instead, aims to sustain the MV DC link voltage. The active current set-point depends on the MV
DC link and the reactive current set-point can be modified to sustain the voltage in the MV grid. Eventually, harmonic contents can be added both in the active and reactive current set-points in order to perform harmonic compensation in specific MV grid buses.

\section{B. Proposed Control for Parallelizing the ST with CPT}

The aforementioned control works just in case the ST has a "grid-forming" role in LV grid. As the ST is connected in parallel with a CPT, the control changes as described in Fig. 2(b) (marked in red). The LV side does not control anymore the voltage waveform in LV grid, due to the presence of the CPT, but it controls the active current in order to keep the LV $\mathrm{DC}$ link at the nominal value. The reactive current is a degree of freedom for enhancing the voltage control in LV grid. The DC-DC converter (DAB) controls the power flow in order to control the MV DC link voltage.

The MV AC/DC stage, instead, can control freely the active and reactive power injection in the MV grid, controlling the $\mathrm{AC}$ current. This feature, together the reactive power support in LV grid, gives to the ST high voltage support and harmonic compensation capability, both in LV and MV grids. The LV and MV reactive power controller can sustain the voltage profile and compensate the CPT voltage drop. In case of installation in PV and wind power plants, the ST can improve the current profile on the MV side, offering harmonic compensation services to the MV grid.

\section{CONVENTIONAL TRANSFORMER ElECtROMAGNETIC CHARACTERISTICS}

As shown in Fig. 1, the RPGSs are integrated into the grid by the CPT, which affects system performance. Thus, the performances of the CPT are discussed as follows.

\section{A. CPT Performances}

For simplicity, the RPGSs, as shown in Fig. 1, can be assimilated to one converter in series with $\mathrm{CPT}$, and its single- 
phase equivalent circuit is shown in Fig. 3, where subscripts "1" and " 2 " represent the CPT primary and secondary side variables, respectively. The converter current $i_{2}$ is directly controlled, while CPT current $i_{1}$ is indirectly controlled.

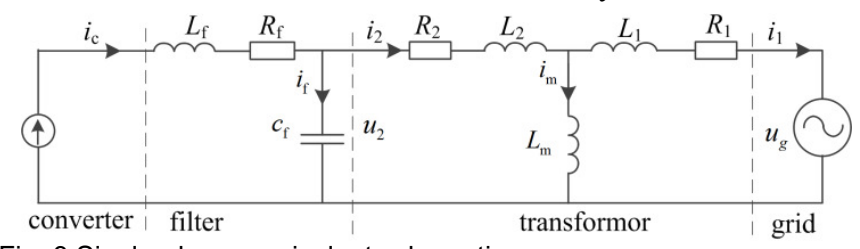

Fig. 3 Single-phase equivalent schematic

By transforming all variables into the primary side and aligning into the grid voltage vector, in the synchronous reference frame, the voltage equation can be expressed as,

$$
\left\{\begin{array}{l}
u_{1 \mathrm{~d}}=u_{2 \mathrm{~d}}=U_{\mathrm{m}} \\
u_{1 \mathrm{q}}=u_{2 \mathrm{q}}=0
\end{array}\right.
$$

where $U_{\mathrm{m}}$ is voltage amplitude.

By considering the voltage drop across the resistance and leakage inductance, the transformer flux can be expressed as,

$$
\left\{\begin{array}{l}
\varphi_{1 \mathrm{~d}}=\psi_{\mathrm{m}} \sin \theta \\
\varphi_{1 \mathrm{q}}=-\psi_{\mathrm{m}} \cos \theta
\end{array}\right.
$$

where $\psi_{\mathrm{m}}$ is the flux linkage amplitude, $\theta$ is the angle caused by voltage drop.

The voltage equation can be expressed as,

Based on the relation between flux and currents, the primary side current can be obtained as,

$$
\left\{\begin{array}{l}
i_{1 \mathrm{~d}}=\frac{\varphi_{1 \mathrm{~d}}-L_{\mathrm{m}} i_{2 \mathrm{~d}}}{L_{1}} \\
i_{1 \mathrm{q}}=\frac{\varphi_{1 \mathrm{q}}-L_{\mathrm{m}} i_{2 \mathrm{q}}}{L_{1}}
\end{array}\right.
$$

By substituting(1), (2) and (4) into(3), it can be obtained the time derivative of flux amplitude and angle,

$$
\left\{\begin{array}{l}
\frac{d \psi_{\mathrm{m}}}{d t}=U_{\mathrm{m}} \sin \theta+\frac{L_{\mathrm{m}} R_{1} i_{2 \mathrm{~d}}}{L_{1}} \sin \theta-\frac{L_{\mathrm{m}} R_{\mathrm{l}} i_{2 \mathrm{q}}}{L_{1}} \cos \theta-\frac{R_{\mathrm{l}}}{L_{1}} \psi_{\mathrm{m}} \\
\frac{d \theta}{d t}=\frac{U_{\mathrm{m}} \cos \theta+\frac{L_{\mathrm{m}} R_{1} i_{2 \mathrm{~d}}}{L_{1}} \cos \theta+\frac{L_{\mathrm{m}} R_{1} i_{2 \mathrm{q}}}{L_{1}} \sin \theta}{\psi_{\mathrm{m}}}-\omega_{\mathrm{s}}
\end{array}\right.
$$

Based on (5), the state equation can be expressed as,

$$
\dot{x}=f(x, u)
$$

where $x=\left[\psi_{\mathrm{m}}, \theta\right]^{T}$ and $u=\left[i_{\mathrm{ld}}, i_{1 \mathrm{q}}\right]^{T}$.

By linearizing (6) at equilibrium point, it derives that,

$$
\triangle \dot{x}=A \triangle x+B \Delta u
$$

$$
B=\left|\begin{array}{ll}
\frac{\partial f_{1}}{\partial u_{1}} & \frac{\partial f_{1}}{\partial u_{2}} \\
\frac{\partial f_{2}}{\partial u_{2}} & \frac{\partial f_{2}}{\partial u_{2}}
\end{array}\right|, A=\left|\begin{array}{ll}
\frac{\partial f_{1}}{\partial x_{1}} & \frac{\partial f_{1}}{\partial x_{2}} \\
\frac{\partial f_{2}}{\partial x_{1}} & \frac{\partial f_{2}}{\partial x_{2}}
\end{array}\right|=\left|\begin{array}{cc}
-\frac{R_{1}}{L_{1}} & U_{\mathrm{m}} \cos \theta_{0}+\frac{L_{\mathrm{m}} R_{1} i_{2 \mathrm{~d}}}{L_{1}} \cos \theta_{0}+\frac{L_{\mathrm{m}} R_{1} i_{2 \mathrm{q}}}{L_{1}} \sin \theta_{0} \\
-\frac{U_{\mathrm{m}} \cos \theta_{0}+\frac{L_{\mathrm{m}} R_{1} i_{2 \mathrm{~d}}}{L_{1}} \cos \theta_{0}+\frac{L_{\mathrm{m}} R_{\mathrm{l}} i_{2 \mathrm{q}}}{L_{1}} \sin \theta_{0}}{\psi_{\mathrm{m} 0}^{2}} & \frac{-U_{\mathrm{m}} \sin \theta_{0}-\frac{L_{\mathrm{m}} R_{1} i_{2 \mathrm{~d}}}{L_{1}} \sin \theta_{0}+\frac{L_{\mathrm{m}} R_{1} i_{2 \mathrm{q}}}{L_{1}} \cos \theta_{0}}{\psi_{\mathrm{m} 0}}
\end{array}\right|
$$

At the equilibrium point,

$$
\left\{\begin{array}{l}
\sin \theta_{0}=0 \\
\cos \theta_{0}=1
\end{array} \text { and } \begin{array}{l}
d \psi_{\mathrm{m} 0} / d t=0 \\
d \theta_{0} / d t=0
\end{array}\right.
$$

By substituting (9) into (8), it results in,

$$
s I-A=\left|\begin{array}{cc}
s+\frac{R_{1}}{L_{1}} & \psi_{\mathrm{m}} \omega_{\mathrm{s}} \\
\frac{\omega_{\mathrm{s}}}{\psi_{\mathrm{m}}} & s+\frac{R_{1}}{L_{1}}
\end{array}\right|
$$

The characteristic eigenvalues can be obtained as,

$$
\lambda_{1,2}=-\frac{R_{1}}{L_{1}} \pm 2 j \omega_{\mathrm{s}}
$$

Due to the high power, the CPT resistance is very small. Consequently, the real parts of eigenvalues are close to the imaginary axis. It leads to the system low damping. In other words, the system will oscillate. In order to overcome this issue, a mathematical analysis of the electromagnetic characteristics is needed.

\section{B. Transformer's Electromagnetic Characteristic}

The CPT primary side voltage equation can be expressed as,

$$
\vec{u}_{1}=R_{1} \vec{i}_{1}+\frac{d \vec{\varphi}_{1}}{d t}
$$

By neglecting control delay, the converter current can be expressed as,

$$
\vec{i}_{2}=\vec{i}_{2 \text { ref }}
$$

Based on (4) and (13), it can deduce that,

$$
\overrightarrow{i_{1}}=\frac{\vec{\varphi}_{1}-L_{\mathrm{m}} \vec{i}_{2 \text { ref }}}{L_{1}}
$$

By substituting (14) into (12), the time derivative of flux can be obtained as,

$$
\vec{u}_{1}=\frac{R_{1}}{L_{1}} \vec{\varphi}_{1}+\frac{d \vec{\varphi}_{1}}{d t}-\frac{R_{1} L_{\mathrm{m}}}{L_{1}} \vec{i}_{2 \text { ref }}
$$

Based on (15), the flux can be obtained as,

$$
\vec{\varphi}_{1}=c e^{-\frac{t}{\tau}}+\frac{\vec{u}_{1}}{j \omega_{\mathrm{s}}+1 / \tau}-\frac{L_{\mathrm{m}}}{\tau} \frac{\vec{i}_{2 \mathrm{ref}}}{j \omega_{\mathrm{s}}+1 / \tau}
$$

where $\tau=L_{1} / R_{1}$.

By substituting (16) into (14), the converter connected CPT output current can be obtained as,

$$
\vec{i}_{1}=\frac{c}{L_{1}} e^{-\frac{t}{\tau}}+\frac{1}{L_{1}} \frac{\vec{u}_{1}}{j \omega_{\mathrm{s}}+1 / \tau}-\frac{L_{\mathrm{m}}}{L_{1} \tau} \frac{\vec{i}_{2 \_ \text {ref }}}{j \omega_{\mathrm{s}}+1 / \tau}-\frac{L_{\mathrm{m}}}{L_{1}} \vec{i}_{2 \_ \text {ref }}
$$

The first term on the right hand of (17) is a decaying component, and it will be equal to zero during steady state. However, if the power grid voltage is perturbed, the CPT 
output current includes the decaying component, leading to current distortion and active/reactive power oscillation.

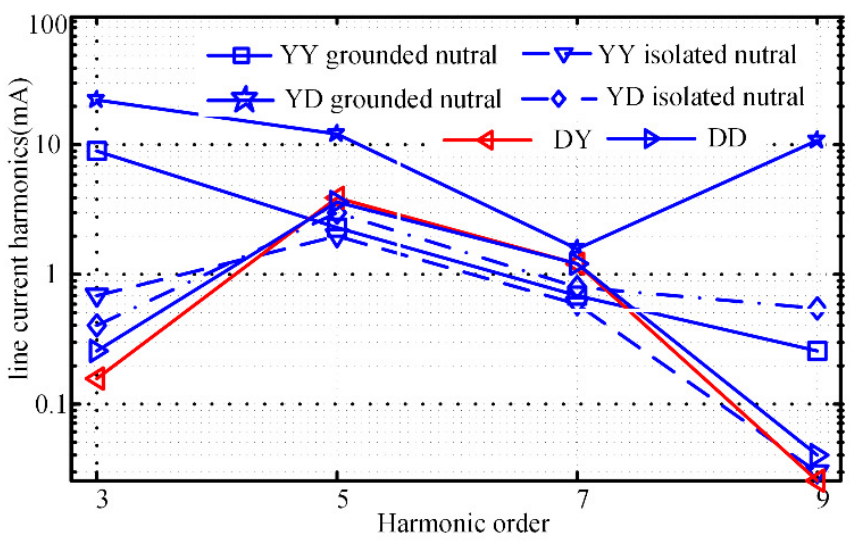

Fig. 4 Harmonic content of line current under different connection [19]

\section{Magnetizing Current Harmonics}

The exciting current harmonics of the CPT have been discussed in detail in $[19,20]$. In order to show the effects of this problem, the exciting current distortion is shortly studied as follows.

There are two main causes for the exciting current distortion. Firstly, the connection type of the primary and secondary side windings and, secondly, the supply voltage harmonic both may result in the exciting current distortion. In practice, there are various types of winding connection and the three-phase supply always presents some degree of imbalance and harmonic distortion. With the same supply voltage, the exciting current harmonics are compared in Fig. 4.

\section{IMPROVED CONTROL STRATEGY BASED ON PARALLEL CONNECTION OF ST AND CPT}

As analyzed above, reactive power support and distorted current compensation need to be solved for large RPGSs. The parallel connection of ST and CPT is proposed to reduce cost and improve system performance, as shown in Fig. 1 (highlight in dash line).

\section{A. Reactive Power Compensation}

The parallel connection of the ST and CPT and its power flow are shown in Fig. 5. The main active power $P_{\mathrm{g}}$ flows through the CPT, and compensating active power $P_{\mathrm{L}}$ and $P_{\mathrm{M}}$ flow through the ST. The reactive power can be supplied by ST from both the LV and MV side, $Q_{\mathrm{L}}$ and $Q_{\mathrm{M}}$, respectively.

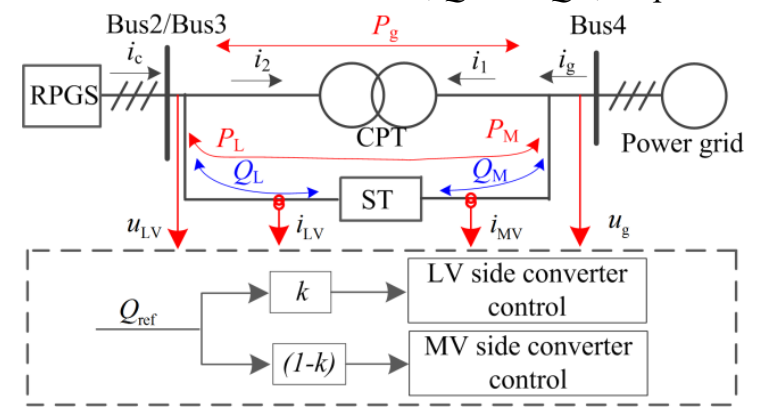

Fig. 5 Reactive power control for parallel connection of $\bar{S} \bar{T}$ and $\bar{C} \overline{\text { CPT }}$

During grid voltage drop, the set point of reactive power, $Q_{\text {ref, can }}$ be obtained. Then a coefficient $k$ is used to dispatch the injected reactive power for LV and MV side converter, as shown in Fig. 5. Due to the step-up transformer, the turn ratio needs to be considered for calculating the MV LV side reference current. As the detailed control design is similar to the conventional STATCOM $[35,36]$, it is omitted in Fig. 5.

Comparison of the proposed strategy and the conventional STATCOM for reactive power injection is carried out in PSCAD. As the simulation model of transformer is ideal, it cannot clearly show the distorted current components caused by the magnetizing current, which evidently exists in practice. Thus, the system-level impact is validated by means of an IEEE 34-bus model. In the scheme proposed in this paper, the ST deals with just a fraction of CPT nominal power (i.e., 20\%).

In order to make a fair comparison between the proposed strategy and STATCOM, only reactive power compensation is analyzed. Both devices are implemented in bus 860: the ST, sized $200 \mathrm{kVA}$, is connected in parallel to a 1MW CPT; the STATCOM is connected to the LV side of the CPT with a size of $400 \mathrm{kVA}$. This makes fair the comparison between the two devices. Downstream the transformer a $1 \mathrm{MW}$ wind turbine injects $20 \mathrm{~kW}$. At the time $0.2 \mathrm{~s}$, a reactive power step is requested. The ST injects $200 \mathrm{kVAr}$ in $\mathrm{LV}$ and $200 \mathrm{kVAr}$ in MV grids, instead the STATCOM injects $400 \mathrm{kVAr}$ in LV grid. The results of this power step are shown in Fig. 6. If the ST is more effective than a STATCOM in terms of voltage support in MV grid, the behavior in LV grid is different. The STATCOM, injecting the same amount of reactive power of ST directly in LV, increases the voltage near 1.05 p.u., and it results more effective than the ST in controlling the voltage in LV grid (Fig. 6(a)). However, the ST voltage support is more effective in MV grid considering the same amount of reactive power, as shown in Fig. 6(b).
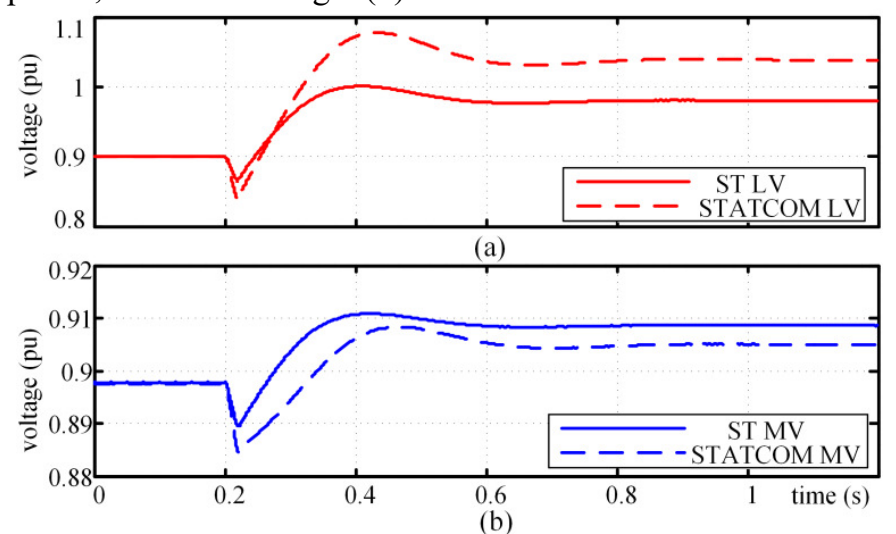

Fig. 6 Simulation results voltage profiles before and after the reactive power step: (a) in LV grid in case of ST (red line) and STATCOM (red dotted line), and (b) in MV grid in case of ST (blue line) and STATCOM (blue dotted line).

\section{B. Power Quality Improved Strategy Based on ST}

In this part, the proposed strategy focuses on the grid current harmonics suppression and performance improvement. The ST control structure diagram is shown in Fig. 7. A vector current control, based on proportional, integral and resonant (PIR) controller in the dq reference frame, is adopted. As RPGS usually works with unity power factor, by neglecting 
the control system delay, the RPGS output current can be simplified expressed as,

$$
\left\{\begin{array}{l}
i_{\mathrm{d} 2}=i_{\mathrm{d} 2 \text { ref }} \\
i_{\mathrm{q} 2}=0
\end{array}\right.
$$

where $i_{2 \mathrm{~d}}$ ref $i s$ the maximum power point current.

Based on (4), it can be obtained that,

$$
\left\{\begin{array}{l}
i_{\mathrm{d} 1}=-i_{\mathrm{d} 2 \text { ref }} \\
i_{\mathrm{q} 1}=-\frac{U_{\mathrm{m}}}{\omega_{\mathrm{s}}}
\end{array}\right.
$$

It depicts that the power factor in primary side of CPT is not equal to zero, even if the secondary side power factor is zero, due to the presence of the transformer magnetizing current.

In order to achieve unity power factor in MV side, the ST reference current is derived as,

$$
\left\{\begin{array}{l}
i_{\mathrm{MV} \_\mathrm{d} 2 \text { ref }}=0 \\
i_{\mathrm{MV} \_\mathrm{q} 2 \text { ref }}=i_{\mathrm{q} 1}
\end{array}\right.
$$

As analyzed in (16) and (17), during grid voltage fluctuations, the primary side flux and current have decaying components, degrading the grid current quality. In order to suppress this effect, the ST reference current is given as,

$$
\vec{i}_{\mathrm{MV} \_ \text {ref }}=\frac{\vec{\varphi}_{1}-\vec{u}_{1} / \omega_{\mathrm{s}}}{L_{1}}
$$

The ST MV side reference currents are equal to zero, during steady state, while the reference currents are unequal to zero during grid voltage variations because of the decaying flux in (16). The reference current of ST MV side is equal to the sum of (20) and (21).

Based on the relation between the flux and current, the grid current, as shown in Fig. 7, can be obtained as,

$$
\overrightarrow{i_{\mathrm{g}}}=\frac{\vec{\varphi}_{1}-L_{\mathrm{m}} \vec{i}_{2}-L_{1} \vec{i}_{\text {st_ref }}}{L_{1}}
$$

By substituting(18), (20), (21) into (22), it can been obtained that,

$$
\overrightarrow{i_{\mathrm{g}}}=-\frac{L_{\mathrm{m}}}{L_{1}} \vec{i}_{2}
$$

Compared to (17), the proposed strategy can ensure that the grid current in (23) is linear to the converter output current, without any effects of the CPT.

As analyzed in Section III $C$, in practice the CPT magnetizing current has large harmonic components. Additional, the power grid also exists harmonic current caused by nonlinear loads. Therefore, the reference current is calculated directly by (20) and (21) cannot suppress the harmonic current properly. In order to overcome the effects of these un-modelled factors, a corrective approach has to be proposed.

In the synchronous reference frame, the fundamental component becomes DC component, but others become AC components.

$$
\vec{i}_{\mathrm{g}}=\vec{i}_{\mathrm{gdc}}+\vec{i}_{\mathrm{gh}}
$$

where subscript "gh" represent the h-order harmonic current in MV grid.

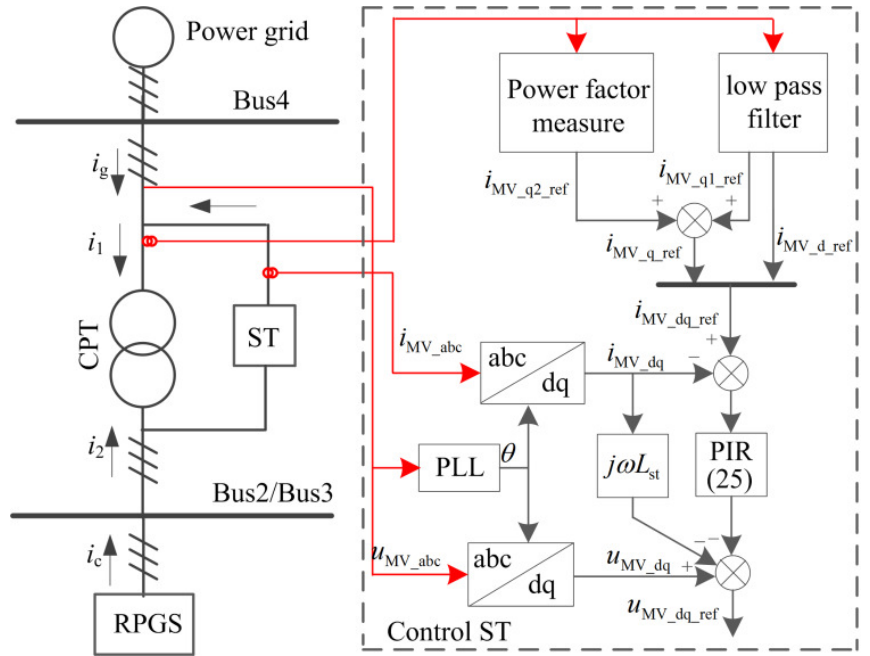

Fig. 7 Control structure diagram for ST

Based on this characteristic, a low pass filter is adopted to obtain distorted components, which are used as ST current reference. In order to suppress AC distorted currents, the corresponding resonant controller is designed as,

$$
G_{\mathrm{r}}(s)=k_{\mathrm{p}}+\sum_{h=0}^{n} \frac{k_{\mathrm{h}} s}{s^{2}+\omega_{\mathrm{ch}} s+\omega_{\mathrm{h}}^{2}}
$$

where $k_{\mathrm{p}}$ and $k_{\mathrm{h}}$ are the proportional and resonant gains, respectively, $\omega_{\mathrm{h}}$ is the resonant angular frequency, and $\omega_{\mathrm{ch}}$ is the damping coefficient.

Based on previous analysis, the control diagram for harmonic suppression is shown in Fig. 7. By measuring the power factor in the power grid, the reference current $i_{\mathrm{MV} \_\mathrm{q} 2 \text { ref }}$ can be obtained, allowing to control Bus4 with unity power factor. In addition, by measuring the current harmonics, the reference currents $i_{\mathrm{MV} \_\mathrm{q} 1 \text { ref }}$ and $i_{\mathrm{MV} \text { __ ref }}$ can be obtained. The sum of $i_{\mathrm{MV} \_}$1_ref and $i_{\mathrm{MV} \_\mathrm{q} 2 \text { ref }}$ is total q-axis reference current.

\section{EXPERIMENTAL RESULTS}

In order to validate the effectiveness of the proposed strategy in power quality improvement, a $5.5 \mathrm{~kW}$ experimental setup has been built in laboratory. The setup picture and structure diagram are shown in Fig. 8. A Chroma programmable AC source was used as a grid emulator to generate grid faults. The DC source and the grid side converter (GSC) were used to simulate the PV or wind turbine DC-link and the grid-tied converter. A 10kVA delta-wye CPT was used as an isolation transformer. The setup and the control parameters are listed in Table I and Table II, respectively. The system was controlled by dSPACE1006.

\section{A. Steady- and Transient State Performance of CPT}

In order to clearly show the effects from the CPT, its electromagnetic characteristics are tested in lab based on the $10 \mathrm{kVA}$ transformer. The measured exciting current of the CPT under various voltage amplitudes is shown in Fig. 9. The exciting currents are highly distorted, which increases the grid current harmonics even during steady state. This problem becomes evident in case of low CPT active current. Compared to the $\mathrm{kVA}$ power transformer, the MW transformer has larger exciting current, which results in grid current high distortion. 


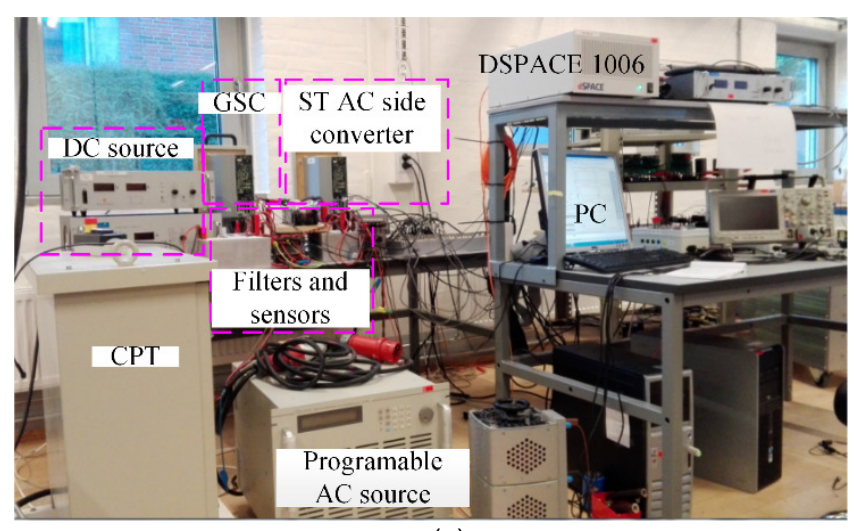

(a)

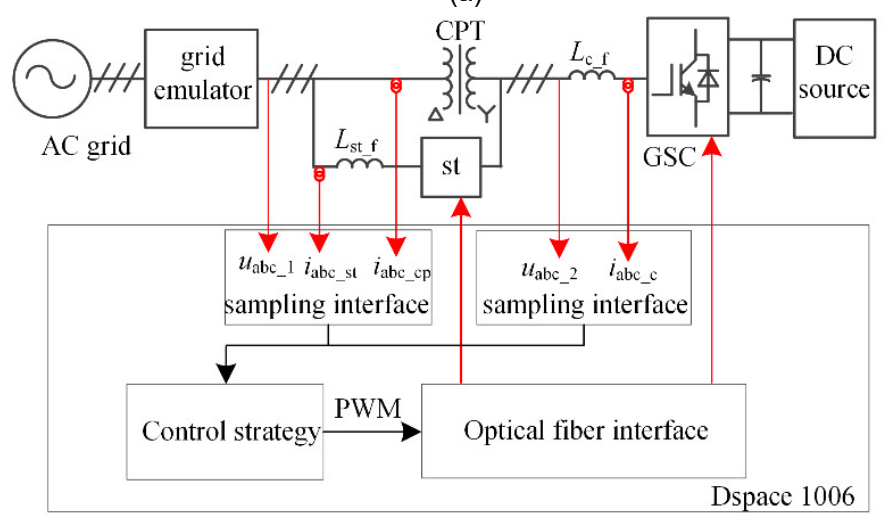

(b)

Fig. 8 The experimental setup (a) experimental setup photograph (b) system structure diagram

TABLE I

SETUP PARAMETERS

\begin{tabular}{|l|l|}
\hline \multicolumn{2}{|c|}{ Isolation power transformer } \\
\hline Connection & DY11 \\
\hline Rated capacity & $10 \mathrm{kVA}$ \\
\hline Rated frequency & $50 \mathrm{~Hz}$ \\
\hline Turn ratio(n $\left.\mathrm{n}_{1} / \mathrm{n}_{2}\right)$ & 1.732 \\
\hline \multicolumn{2}{|c|}{ GSC } \\
\hline Rated power & $5.5 \mathrm{kVA}$ \\
\hline Filter inductance $L_{\mathrm{c}_{\mathrm{f}} \mathrm{f}}$ & $3.3 \mathrm{mH}$ \\
\hline ST AC side converter \\
\hline Rated power & $5.5 \mathrm{kVA}$ \\
\hline Filter inductance $L_{\mathrm{st} \_\mathrm{f}}$ Grid & $3.3 \mathrm{mH}$ \\
\hline \multicolumn{2}{|c|}{} \\
\hline Grid rated frequency & $50 \mathrm{~Hz}$ \\
\hline Grid rated voltage & $380 \mathrm{~V}$ \\
\hline
\end{tabular}

TABLE II

EXPERIMENTAL CONTROLLER PARAMETERS

\begin{tabular}{|l|l|}
\hline \multicolumn{2}{|c|}{ PI controller for GSC } \\
\hline$K_{\mathrm{p}}$ & 30 \\
\hline$K_{\mathrm{i}}$ & 300 \\
\hline \multicolumn{2}{|c|}{ PIR controller for ST AC side converter } \\
\hline$K_{\mathrm{p}}$ & 30 \\
\hline$K_{\mathrm{i}}$ & 300 \\
\hline$K_{\mathrm{r} \_1}$ & 300 \\
\hline$\omega_{\mathrm{c} 1}$ & 20 \\
\hline$\omega_{1}$ & $314 \mathrm{rad}$ \\
\hline$K_{\mathrm{r} \_}$ & 300 \\
\hline$\omega_{\mathrm{c} 2}$ & 150 \\
\hline$\omega_{2}$ & $628 \mathrm{rad}$ \\
\hline
\end{tabular}

Besides the effects during steady state, the electromagnetic characteristic of the CPT during grid faults is measured, as shown in Fig. 10. When the three-phase voltage drops from $220 \mathrm{~V}$ to $0 \mathrm{~V}$ rms, the exciting current decays to zero in more than 1.0s, (Fig. 10(a)). Similarly, when three-phase voltage recovers from $60 \mathrm{~V}$ to $150 \mathrm{~V}$ rms, the exciting current has a large ripple and the transient current decays to zero in more than 1.0s, (Fig. 10(b)). This matches well with the theoretical analysis. For the MWs CPT, the winding resistance is much smaller, which leads to longer transient state and larger current ripple.

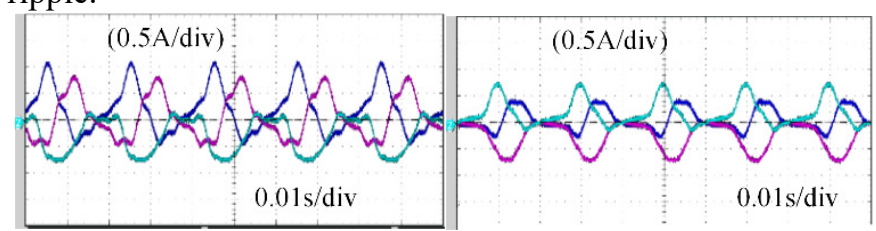

(a)

(b)

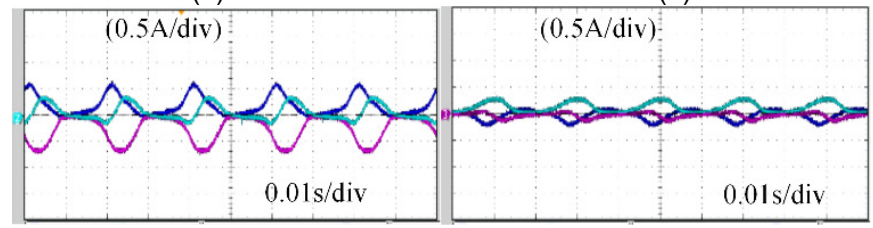

(c)

(d)

Fig. 9 Experimental results of the CPT exciting current under threephase voltage rms is (a) $200 \mathrm{~V}$, (b) $140 \mathrm{~V}$, (c) $90 \mathrm{~V}$, and (d) $60 \mathrm{~V}$
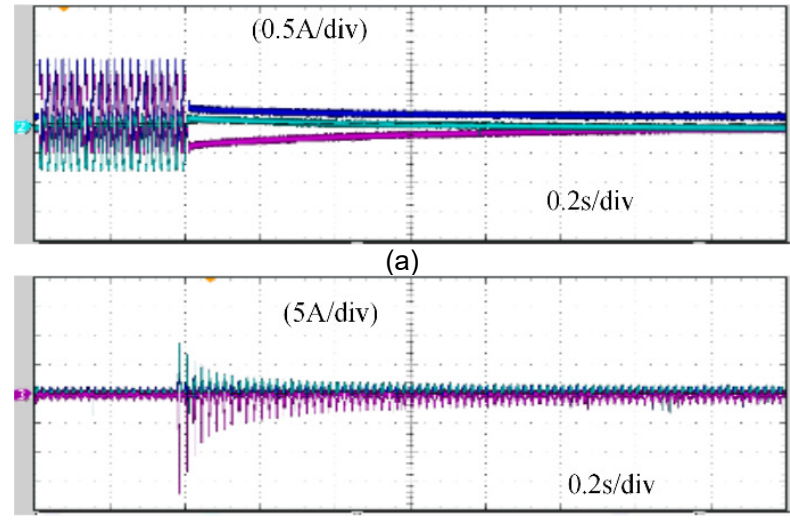

(b)

Fig. 10 Experimental results of dynamic Electro-magnetic characteristic during (a) grid voltage sag, and (b) grid voltage recovery

\section{B. Power Grid Current Quality with Improved Strategy}

The effects of the CPT exciting current during steady state on power grid are shown in Fig. 11 (a), where the GSC works at unity power factor and the output active current amplitude is 3.0A. As the secondary side current of CPT is controlled by the GSC, the CPT exciting current is supplied from the primary side completely. Fig. 11(a) shows that although the GSC currents are sinusoidal, the CPT primary side current and grid current are highly distorted, with a THD of $10.24 \%$. This validates the theoretical analysis that the exciting current degrades grid current quality. Besides the current, the active and reactive powers show the same behaviors. Since the amplitude of exciting current of the 10kVA transformer adopted in the setup is very small (Fig. 9), it does not have an evident effect on the power factor in the grid. The experimental results clearly show how the CPT affects the grid power quality, although the GSC can effectively control the currents.

In contrast, the proposed strategy can significantly improve the grid current quality, as shown in Fig. 11(b). Compared to Fig. 11(a), the grid current THD is reduced from $10.24 \%$ to $5.22 \%$. Additionally, the active and reactive powers of the power grid are both improved as compared to Fig. 11(a). 
These results clearly show that the proposed strategy can improve system performances during normal condition.

When grid voltage is unbalanced, the impacts of the CPT on power grid currents are shown in Fig. 12, where three-phase voltage effective values are $70 \mathrm{~V}, 110 \mathrm{~V}$ and $110 \mathrm{~V}$. Without the ST, the grid currents are seriously distorted with a THD of

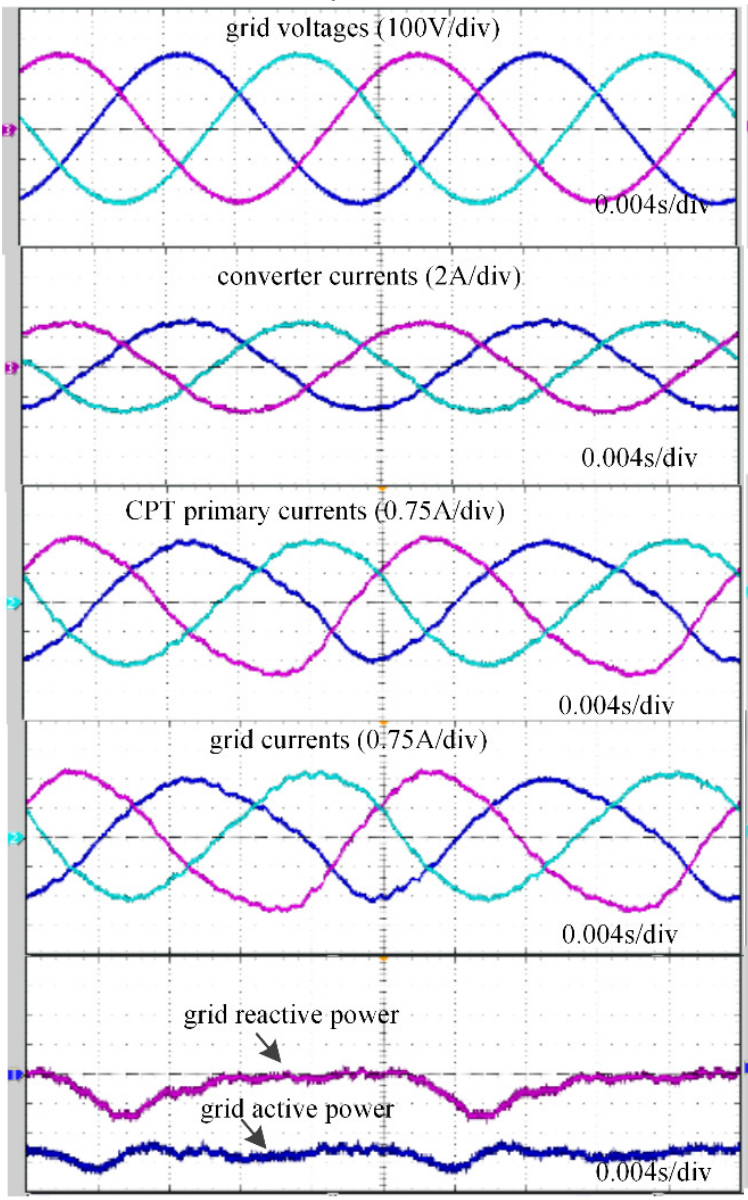

(a)
$10.32 \%$ as shown in Fig. 12(a). In contrast, with the proposed strategy, the grid current quality is improved and the THD is 5.31\%, as shown in Fig. 12(b). Fig. 11 and Fig. 12 both validate that the proposed strategy can significantly improve grid current quality.

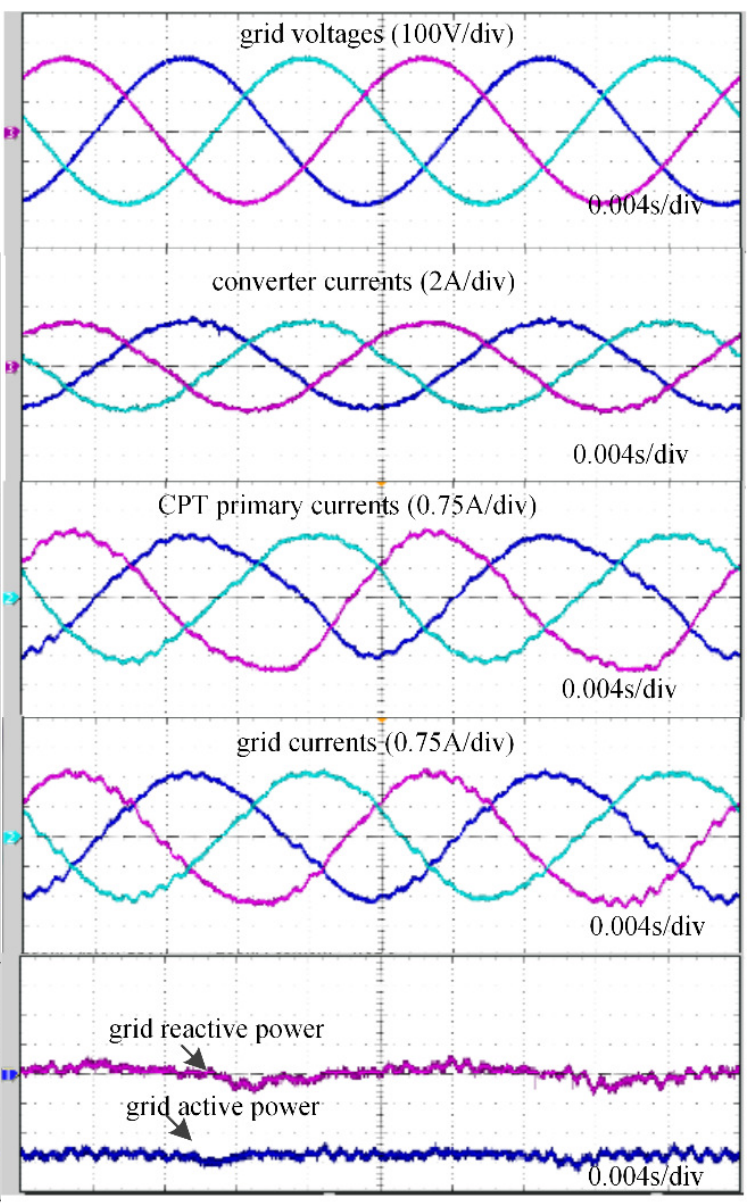

(b)

Fig. 11 Experimental results of power grid performances affected by the CPT nonlinear electromagnetic characteristic, (a) without ST (grid current $\mathrm{THD}=10.24 \%$ ) and (b) with ST (grid current THD=5.22\%)

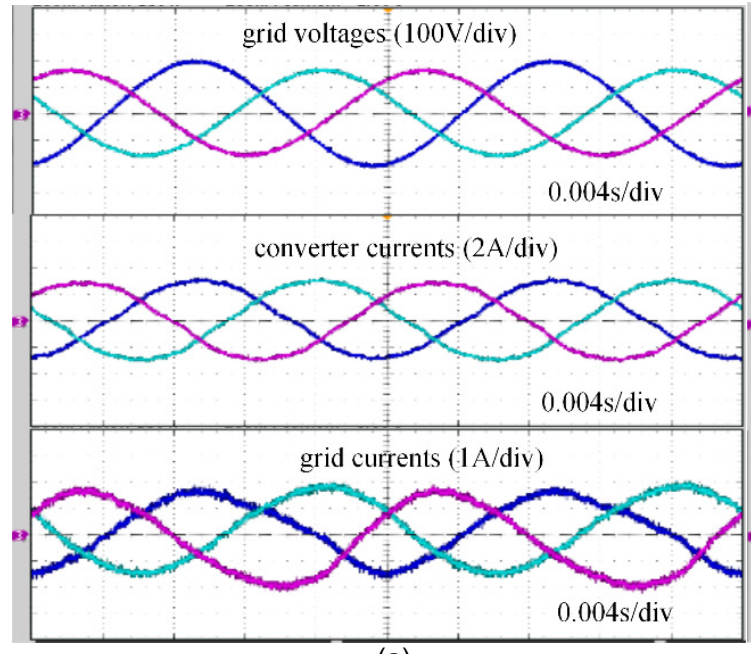

(a)

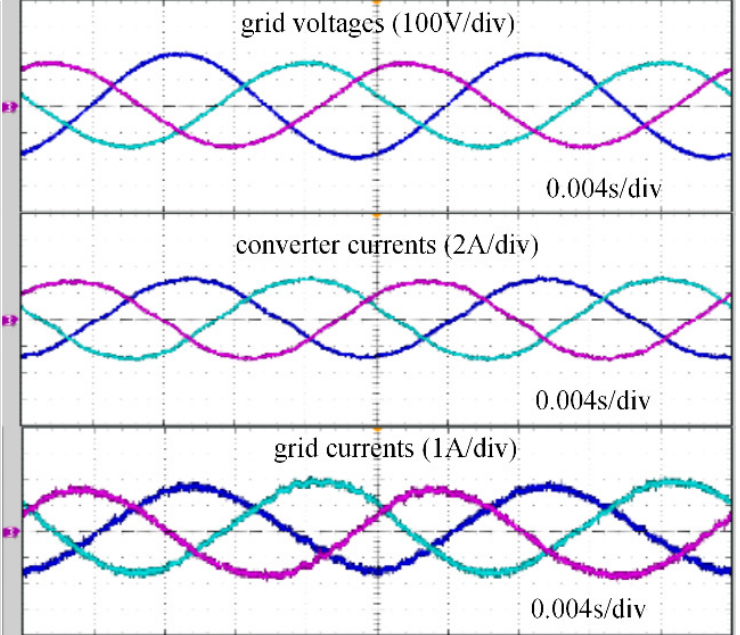

(b)

Fig. 12 Experimental results during unbalanced grid condition (a) without ST (grid current THD=10.32\%) and (b) with ST (grid current THD=5.31\%) C. Power Grid Performances Improved with the Improved Strategy During Grid Faults

Besides the power quality improvement during steady state, the proposed strategy can improve the grid performance during grid faults as well. Compared to the performances 
during grid voltage drop, the CPT has serious effects on the current during grid voltage recovery (Fig. 10). Therefore, the following experimental results are only based on grid voltage recovery. The results during three- and single-phase voltage recovery are shown in Fig. 13 and Fig. 14, respectively.

When three-phase grid voltage recovers after faults, the CPT electromagnetic transient characteristic leads to large current ripple at the instant of voltage recovery, as shown in Fig. 13. The large ripple can be suppressed by the transformer flux compensation strategy [9]. Fig. 13 shows that the CPT electromagnetic characteristic leads to transient current in transformer primary side after grid voltage recovery, although transformer secondary side current does not include the transient current, due to the control of the GSC. This matches well with the theoretical analysis. As the transient current flows into the grid directly, the grid current has the same transient state component, which degrades grid performance, as shown in Fig. 13(a), where the grid active and reactive powers and currents have large ripples as well. In contrast, the proposed strategy can compensate the transient state current and improve grid current quality as shown in Fig. 13(b). The grid currents are symmetrical and sinusoidal and the grid active power and reactive power become smooth.

System performances during unbalanced grid faults are shown in Fig. 14. Before grid voltage recovery, three-phase voltage

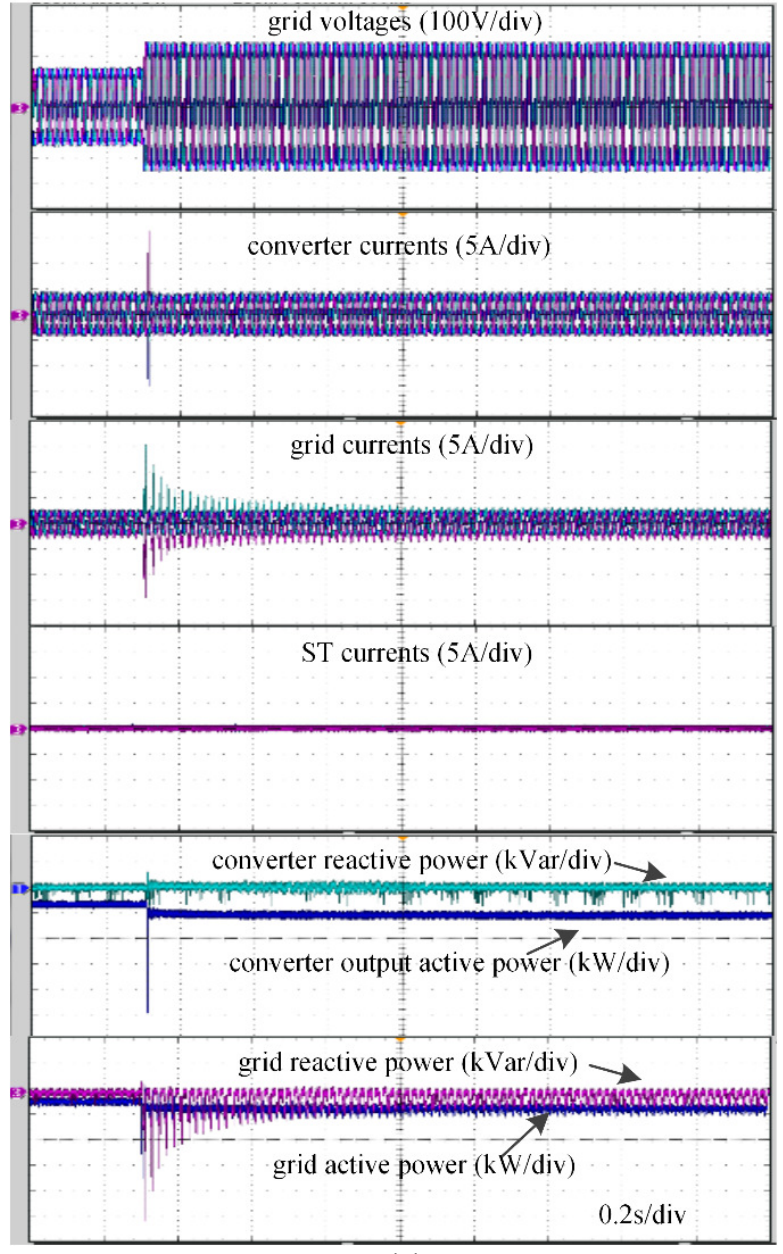

(a) effective values are $60 \mathrm{~V}, 150 \mathrm{~V}$ and $150 \mathrm{~V}$, respectively, and then phase-a voltage recovers to $150 \mathrm{~V}$. Without the ST, grid currents have large ripples after grid voltage recovery, which lead to grid power oscillation, as shown in Fig. 14(a). In contrast, with the proposed strategy, grid current ripple does not exist during grid voltage recovery and the grid power is smooth, as shown in Fig. 14(b).

\section{CONCLUSIONS}

Large photovoltaic and wind systems are connected in rural areas where the grid is weak with long lines. It leads to low grid reliability and stability. Additionally, electromagnetic characteristic of the step-up isolation transformer can significantly degrade the grid power quality in both transient and steady state conditions. The proposed parallel connection of ST and CPT can effectively increase reactive current injection capability and be more effective in supporting MV grid voltage, with respect to a STATCOM of comparable size. The proposed strategy can improve grid current quality during steady state and grid fault conditions. In addition, the parallel structure can significantly reduce the ST power rating requirement. The experimental results, described in this paper, validate the correctness of the theoretical analysis, and show the achieved improvements in the grid power quality.

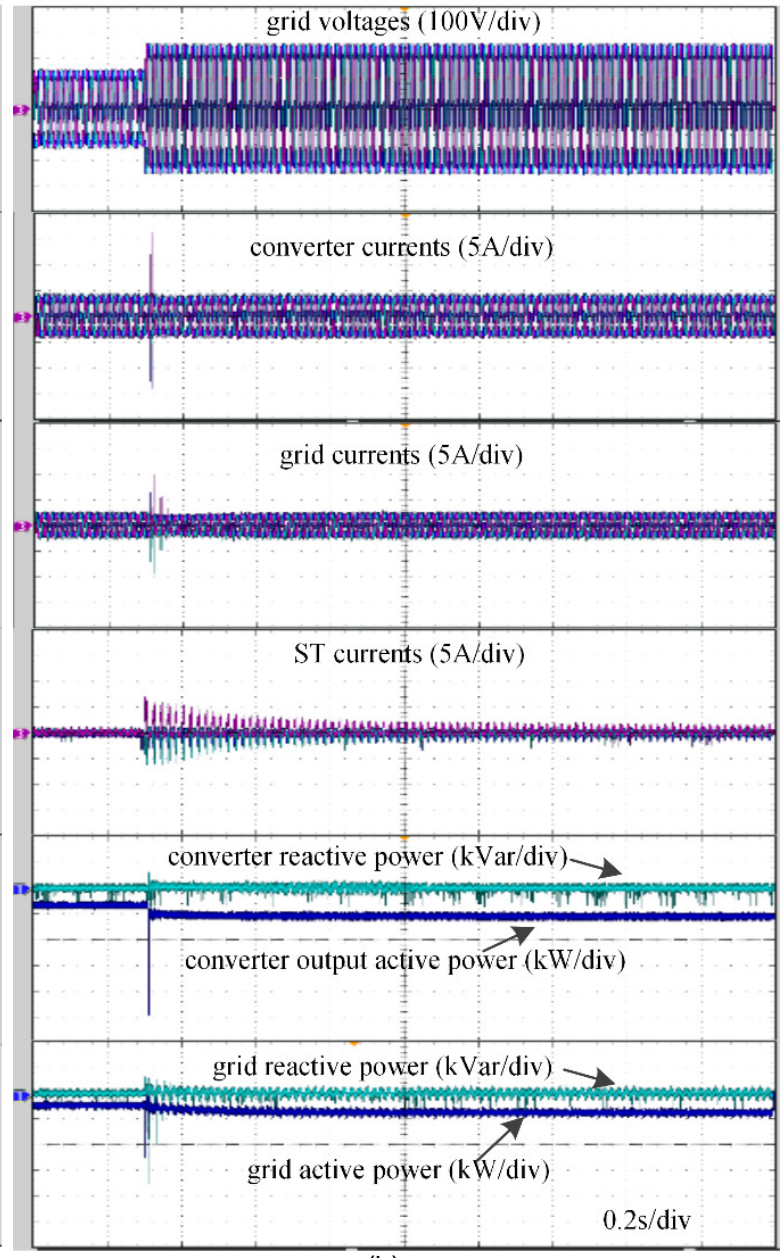

(b)

Fig. 13 Experimental results during three-phase voltage recovery (a) without, and (b) with ST 


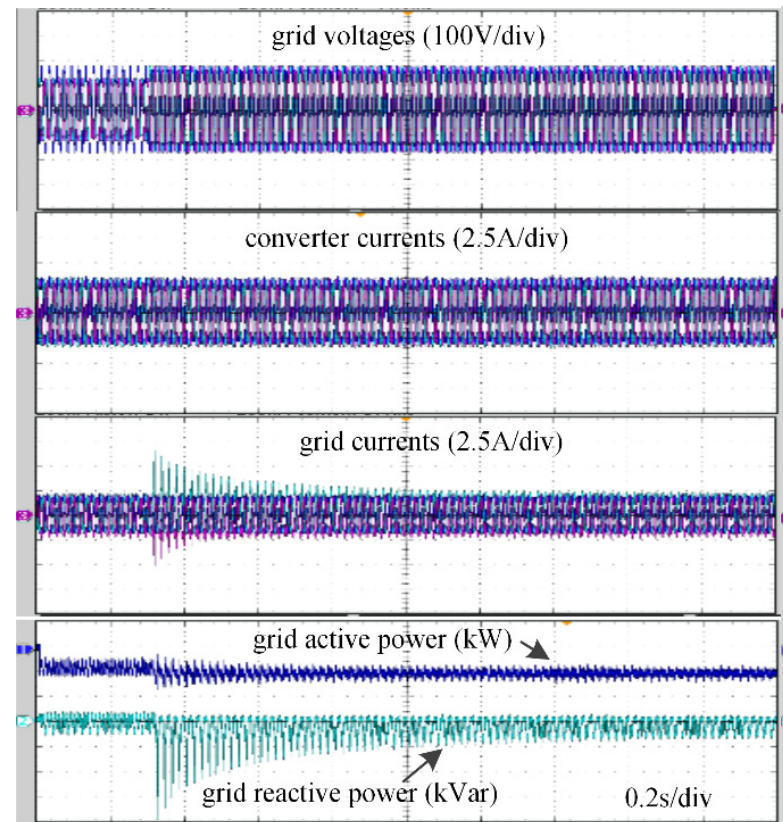

(a)

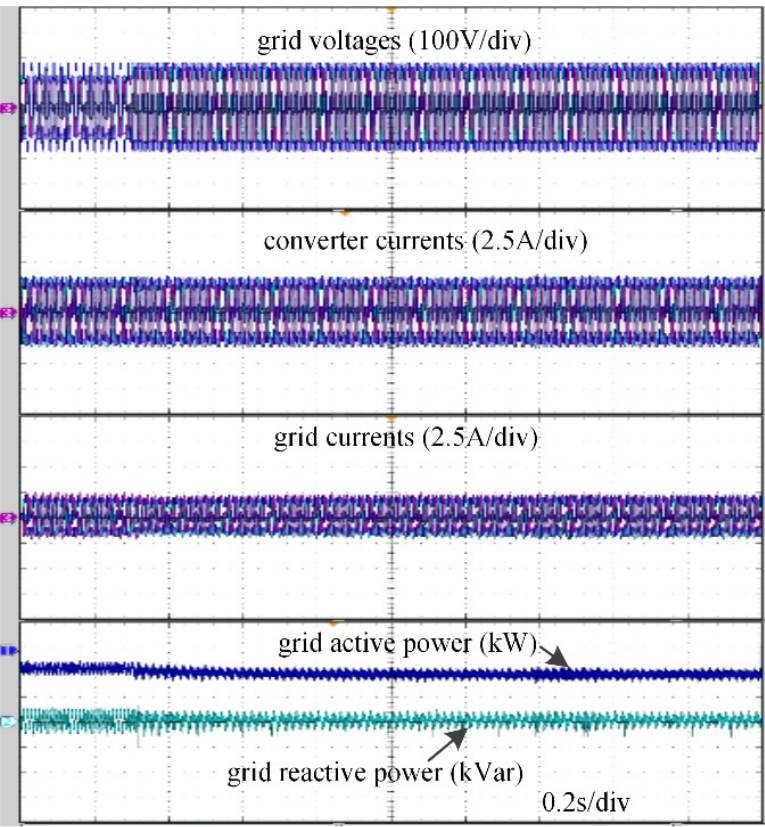

(b)

Fig. 14 Experimental results during single-phase voltage recovery (a) without, and (b) with ST

\section{REFERENCES}

[1] E. M. Ashabani, Y. Mohamed, M. Mirsalim, M. Aghashbani, "Multivariable droop control of synchronous current converters in weak grids/microgrids with decoupled dq-axes currents" IEEE Trans. Smart Grid, vol. 6, no. 4, pp. 1610-1620, Jul. 2015.

[2] F. E. Muljadi, C. Butterfield, B. Parsons, A. Ellis, "Effect of variable speed wind turbine generator on stability of a weak grid" IEEE Trans. Energy Convers. vol. 22, no. 1, pp. 29-36, Mar. 2007

[3] R. Piwko, N. Miller, J. Gasca, X. Yuan, R. Dai, J. Lyons, "Integrating large wind farms into weak power grid with long transmission lines" in Proc. IEEE IPEMC 2006, pp. 1-7.

[4] G. X. Chen, Y. Hou, "STATCOM control for integration of wind farm to the weak grid" in Proc. IEEE PES General Meeting Conference \& Exposition, pp. 1-5, 2014

[5] H. M. Palsson, T. Toftevaag, K. Uhlen, J. Tande, "Large-scale wind power integration and voltage stability limits in regional networks", in Proc. IEEE power engineering society summer meeting, vol. 2, pp. 762$769,2002$.

[6] G. Franceschini, E. Lorenzani, and G. Buticchi, "Saturation compensation strategy for grid connected converters based on line frequency transformers," IEEE Tran., Enegy Convers., vol. 27, pp. 229237, June 2012.

[7] Y. Baghzouz and X. D. Gong, "Analysis of three-phase transformer noload charcteristics," IEEE Tran. Power Sys., vol. 10, pp. 18-26, 1995.

[8] J. C. Rossi and L. C. d. Oliveira, "Experimental analysis of harmonics distortion in excitation currents of double-excited three-phase transformers," Harmonics and Quality of power 2000 Proceeding, vol. 3, pp. 858-863, 2000.

[9] S. F. Chou, C. T. Lee, K. H. C., and P. T. Cheng, "A low-voltage ride through method with transformer flux compensation capability of renewable power grid side converters," IEEE Tran., Power Electron., vol. 29, pp. 1710-1719, April 2014.

[10] G. Buticchi and E. Lorenzani, "Detection Method of the DC Bias in Distribution Power Transformers," in IEEE Transactions on ndustrial Electronics, vol. 60, no. 8, pp. 3539-3549, Aug. 2013.

[11] L. Liu, H. Li, Y. Xue, and W. Liu, "Reactive power compensation and optimization strategy for grid-interactive cascaded photovoltaic systems," IEEE Tran. Power Sys., vol. 30, pp. 188-202, 2015.

[12] L. Liu, H. Li, Z. Wu, and Y. Zhou, "A cascaded photovoltaic system integrating segmented energy storages with self-regulating power allocation control and wide range reactive power compensation," IEEE Tran. Power. Electron., vol. 26, pp. 3545-3559, 2011.

[13] I. E. Camm, C. Edwards, "Reactive compensation system for large wind farms" In proc. Transmission and distribution conference exposition, pp. $1-5,2008$.
[14] B. A. Yogarathinam, J. Kaur, N. R. Chaudhuri "Impact of inertia and effective short circuit ratio on the control of frequency in weak grids interfacing LCC-HVDC and DFIG-based wind farms" IEEE Trans. Power Del. vol.pp, pp. 1-1, 2016.

[15] C. P. Mitra, L. Zhang, L. Harnefors, "Offshore wind integration to a weak grid by SVC-HVDC links using power-synchronoization control: a case study," IEEE Trans. Power Del. vol. 29, no. 1, pp. 453-461, Feb. 2014.

[16] D. L. Zhang, L. Harnefors, H. Nee, "Integration of two very week AC system by VSC-HVDC links using power-synchronization control" IEEE Trans. Power Sys. vol.26, no. 1, pp. 344-355, Feb. 2011.

[17] J. P. Mitra, G. Venayagamoorthy, K. Corzine, "SmartPart as a virtual statcom" IEEE Trans. Smart Grid. vol,2, no. 3 pp. 445-455, Set. 2011.

[18] K. W. Qiao, R. Harley, G. Venazagamoorthy, "Coordinated reactive power control of a large wind farm and STATCOM using heuristic dynamic programming" IEEE Trans. Energy Convers. vol.24, no.2 pp.493-503, Jun. 2009.

[19] R. Kabir, D. Holmes, B. McGrath, L. Meegahapola, "LV grid voltage regulation using transformer electronic tap changing, with PV inverter reactive power injection" IEEE Journal of Emeging and slected topics in power electron., vol. 3, no. 4, pp:1182-1192, Dec. 2015.

[20] X. Liu, A. Aichhorn, L. Liu, H. Li, " Coordinated control of distributed energy storage system with tap changer transformers for voltage rise mitigation under high photovoltaic penetration" IEEE Tran. Smart Grid, vol.3, no. 2, pp:897-906, Jun. 2012.

[21] C. Zhao, D. Dujic, A. Mester, J. K. Steinke, M. Weiss, S. LewdeniSchmid, T. Chaudhuri, and P. Stefanutti, "Power electronic traction transformer-medium voltage prototype," IEEE Trans. Ind. Electron., vol. 61, no. 7, pp. 3257-3268, Jul. 2014.

[22] P. Drabek, Z. Peroutka, M. Pittermann, X. Ce, and M. Dl, "New configuration of traction converter with medium-frequency transformer using matrix converters," IEEE Trans. Ind. Electron., vol. 58, no. 11, pp. 5041- 5048, Nov. 2011.

[23] M. Glinka and R. Marquardt, "A new AC/AC multilevel converter family," IEEE Trans. Ind. Electron., vol. 52, no. 3, pp. 662-669, Mar. 2005.

[24] J. Taufiq, "Power electronics technologies for railway vehicles," in Proc. Power Convers. Conf., 2007, pp. 1388-1393.

[25] J. Burkard, J. Biela, "Evaluation of topologies and optimal design of a hybrid distributiontransformer" 17th European Conf. on Power Electron. and Appl. (EPE'15 ECCE-Europe) pp: 1 -10, 2015.

[26] J. Burkard, J. Biela, "Protection of hybrid transformers in the distribution grid" 18th European Conf. on Power Electron. and Appl. (EPE'16 ECCE-Europe) pp: 1 -10, 2015.

[27] M. Liserre, G. Buticchi, M. Andresen, G. De Carne, L. F. Costa, and Z. X. Zou, "The smart transformer: impact on the electric grid and 
technology challenges," IEEE Ind. Electron. Magazine, vol. 10, pp. 46$58,2016$.

[28] M. Liserre, M. Andresen, L. Costa, G. Butichi, "Power routing in modular smart transformers active thermal control through uneven loading of cells," IEEE Trans. Ind. Electron. vol. 10, no. 3, pp43-53, Sep. 2016

[29] X. She, A. Q. Huang, and R. Burgos, "Review of solid-state transformer technologies and their application in power distribution systems," IEEE Journal of Emerging and Selected Topics in Power Electroni., vol. 1, pp. 186-198, 2013.

[30] S.Bruske, G. De Carne, and M. Lisserre, "Multi-frequency power transfer in a smart transformer based distribution grid," in Proc. 40th Annual Conf. IEEE Ind. Electronic. Society, Dallas, TX, 2014, pp. 43254331.

[31] G. De Carne, G. Buticchi, L. M, C. Yoon, and F. Blaabjerg, "Voltage and current balancing in low and medium voltage grid by means of smart transformer," in Proc. IEEE 2015 Power and Energy Society General Meeting, Denver, Co,, pp. 1-5.

[32] G. De Carne, Z. Zou, G. Buticchi, M. Liserre, and C. Vournas, "Overload control in smart transformer-fed grid," Applied Sciences, 7(2):208, 2017.

[33] G. De Carne, G. Buticchi, M. Liserre, and C. Vournas. "Load control using sensitivity identification by means of smart transformer," IEEE Trans. Smart Grid, Early Access.

[34] G. De Carne, M. Liserre, and C. Vournas, "Online load sensitivity identification in lv distribution grids," IEEE Trans. on Power Sys., Early Access.

[35] Y. Xu, F. Li, "Adaptive PI Control of STATCOM for voltage regulation," IEEE Trans. Power Deli., vol. 29, no. 3, pp:1002-1011, Jun. 2014

[36] T. Aziz, M. J. Hossain, T. Saha, N. Mithulananthan, "VAR planning with Tuning of STATCOM in a DG integrated industrial system" IEEE Trans. Power Deli., vol. 28, no. 2, pp: 875-885, Apr. 2013.

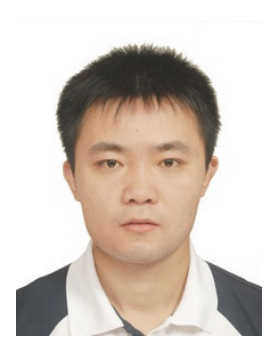

Rongwu Zhu (S'12-M'15) received the B.Eng. in Electrical Engineering from Nanjing Normal University, Nanjing, China, in 2007 and Ph.D. degree in Department of Energy Technology from Aalborg University, Aalborg, Denmark. From 2011-2012, he is a guest researcher with Aalborg University.

$\mathrm{He}$ is currently a Postdoctoral Researcher with Chair of power electronics, at ChristianAlbrechts-University of Kiel (Germany). His research interests include high-power multilevel converters, nonlinear control, DC-grid and wind-farm power systems, smart-transformerfed distribution generation system.

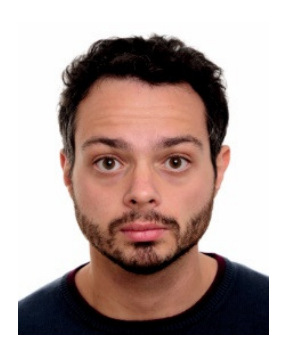

Giovanni De Carne (S'14- M'14) was born in Noci, Bari (Italy) in 1988. He received the bachelor and master degrees in Electrical Engineering from "Politecnico di Bari" (Italy) in 2011 and 2013, respectively. In 2013, he started working on his Ph.D. studies at the Chair of Power Electronics at ChristianAlbrechts Universität zu Kiel, Germany. He is currently working on his $\mathrm{PhD}$ "Analysis of ST features for electric distribution grid" within the ERC Grant project "Highly Reliable And Efficient smart Transformer (HEART)".

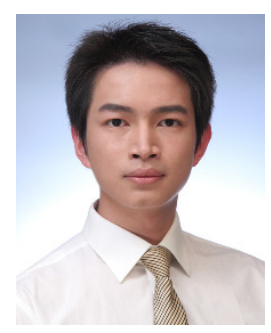

Fujin Deng (S'10-M'13) received the B.Eng. degree in electrical engineering from China University of Mining and Technology, Jiangsu, China, in 2005, the M.Sc. Degree in electrical engineering from Shanghai Jiao Tong University, Shanghai, China, in 2008, and the Ph.D. degree in energy technology from the Department of Energy Technology, Aalborg University, Aalborg, Denmark, in 2012.
He joined the Southeast University in 2017 and is currently a Professor in the School of Electrical Engineering, Southeast University, Nanjing, China. From 2013 to 2015 and from 2015 to 2017, he was a Postdoctoral Researcher and an Assistant Professor, respectively, in the Department of Energy Technology, Aalborg University, Aalborg, Denmark. His main research interests include wind power generation, multilevel converters, high-voltage directcurrent (HVDC) technology, DC grid, and offshore wind farm-power systems dynamics.

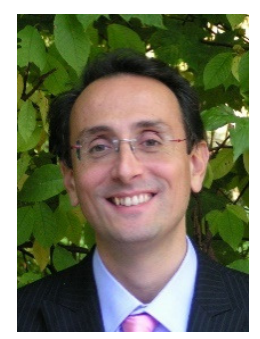

Marco Liserre (S'00-M'02-SM'07-F'13) is a Full Professor and Head of the Chair of Power Electronics at the Christian-AlbrechtsUniversity of Kiel, Kiel, Germany. He has published more than 200 technical papers $(1 / 3$ in international peer-reviewed journals) and a book in second reprint and also translated in Chinese. These works have received more than 15000 citations, for this reason he is listed in the ISI Thomson report "The world's most influential scientific minds" for 2014.

Prof. Liserre has been awarded with a European ERC Consolidator Grant, one of the most prestigious in Europe. He is a member of the IEEE Industry Applications, IEEE Power Electronics, IEEE Power and Energy, and IEEE Industrial Electronics Societies. He has served these societies in various capacities such as Reviewer, Associate Editor, Editor, Conference Chairman, and Track Chairman. He was the founding Editor-in-Chief of the IEEE Industrial Electronics Magazine, founding Chairman of the Technical Committee on Renewable Energy Systems, and IES Vice-President responsible for publications. 